\title{
Popper's achievement
}

SIR - I should like to add to Hermann Bondi's obituary of Sir Karl Popper ( $\mathrm{Na}$ ture 371, 478; 1994). Popper cleared away an error that had entrapped ideas about human rationality since the Greeks.

The rationality of science poses a problem: scientists judge some theories to be better than others. In doing this they reason with arguments. But how do they give that judgement rational authority? From Plato onwards, one approach has dominated: philosophers took the authority of rationality to be in some way transmitted from a source. Popper broke with this tradition. Rationality, he argued, got its authority from our goals - in the case of science - the search for truth. Likewise for the rationality of politics: no source exists for the right rule of society, but we can aim for better ones.

The novelty of his innovation stands out against the history of attempts to fathom the nature of human rationality. This has otherwise been one of many failed attempts to find its source. Plato suggested Forms and Ideas. Others have proposed God, Being, innate or a priori ideas, empirical data, monads, elementary propositions and various types of intuitions and foundations. Sometimes the notion that rationality is linked with truth has been dropped while its origin in a source has been kept: ideological superstructures, social contingencies and epistemes. Even sceptics did not deny that the authority of rationality came from a source, only that it could be transmitted to our beliefs.

This pursuit arises from a basic error: the assumption that because we use sources to back our arguments, the ultimate authority made by arguing rationality - must likewise come from one. But counter-examples exist that dissociate them. Consider air safety: aircraft designs have an authority - airworthiness - that derives from argument and sources - research findings and crash reports. But the authority they make comes from a goal - the desire to fly safe aircraft. No argument can show that an aircraft is safe (we cannot inductively infer that an accident-free aircraft will be so in the future). What argument can do is to let us (or rather civil aviation bodies on our behalf) winnow out unsafe aircraft designs. The more vigorous and exhaustive that search, the more authoritative such judgements are about airworthiness.

The source approach to rationality is also rooted in human experience. As people, we often seek sources of authority to guide what we should do and believe. Children when uncertain look to their parents (social referencing). Uncertain adults, as Stanley Milgram found in his infamous obedience experiments, turn not to their own judgement but to apparent figures of authority. People in religion seek the origins of morality, existence and meaning from supernatural sources. Philosophers often sought in metaphysics a realm of certainty to which they could turn to satisfy such needs for rational beliefs.

That was until Popper. He was the first thinker to explore whether rationality could come from our goals. Whether his suggestions of how we did this--criticism, conjectures and refutations - were the right ones, he asked questions that philosophers should have been asking centuries ago. By venturing to raise and explore them in the twentieth century, he, more than anyone else since the Greeks, changed how we understand the function of reasoning in science and society.

John R. Skoyles

8 Denning Road,

London NW3 1SU, UK

\section{Origins of steady- state theory}

SIR - Whatever may be thought of it now, the steady-state theory of the expanding Universe was an important event in the evolution of cosmology. As there are somewhat contradictory statements about its origin in the literature, we thought it advisable to put together our joint recollections of the history of those days while all three of us are still available.

F.H. awakened a deep interest in astronomy in H.B. and T.G. during our period together during the war, and frequent discussions on questions of astronomy were a central feature of our lives after all three of us returned to Cambridge in 1945-46.

A pressing problem of those days was the discrepancy between Hubble's estimate of his constant and other timescale considerations, as well as questions of the origin of galaxies and of heavy elements. It was T.G. who first proposed the continuous creation of matter at a low but sufficient rate, making it possible to have a universe whose large-scale features remain constant in time. Among the advantages this offered was the removal of the discrepancy between local and cosmological timescales. All three of us debated this idea exhaustively and were then greatly taken with it. But was it publishable merely as an idea?

F.H. then (early 1948) formulated the first version of his $\mathrm{C}$-field theory and offered T.G. co-authorship, which T.G. declined, not wanting to have the first publication tied to so particular a formulation. F.H. then wrote it up as a paper for publication with an acknowledgement to
T.G. Meanwhile, H.B. and T.G. refined their ideas and devised the perfect cosmological principle as well as studying the refutability of their theory in the sense of Popper. Close contact was maintained with F.H. and many discussions were held about this and other topics in astronomy, with F.H. expressing some doubt about H.B. and T.G. using so philosophical a basis.

In spring 1948, H.B. spotted an observational agreement that made publication appropriate. H.B. and T.G. immediately wrote up their phenomenological paper, with much emphasis on the thermodynamics of such a steady-state Universe. This paper (Mon. Not. R. astr. Soc. 108, $252 ; 1948)$ appeared just in front of F.H.'s paper (Mon. Not. R. astr. Soc. 108, 361; 1948 ) in the autumn. This latter paper had been turned down in the spring of 1948 by a well-known physics journal on the curious ground that it was experiencing a shortage of paper.

Hermann Bondi

Churchill College,

Cambridge CB3 ODS, UK

Thomas Gold

Centerfor Radiophysics,

and Space Research,

Cornell University,

Ithaca, New York 14850, USA

Fred Hoyle

102 Admiral's Walk, West CliffRoad,

Bournemouth, Dorset BH2 5HF, UK

\section{Research integrity}

SIR - An article headed "Study proposed on integrity of published data" (Nature 371, 733; 1994) states that Congress's decision to require the National Institutes of Health (NIH) to set up a commission on research integrity was prompted by frustration with the way in which allegations of scientific misconduct have been treated and concern that the NIH's Office of Research Integrity (ORI), which investigates allegations of misconduct, has not been working as well as Congress had hoped.

Although the Congress called for the commission through language in the NIH Revitalization Act, the commission itself was set up by the Department of Health and Human Services (DHHS), with members selected by the DHHS Secretary, Donna Shalala. Moreover, the ORI is not and never has been a part of the NIH. It was established by the Public Health Service (PHS) on 3 June 1992, when NIH's existing Office of Scientific Integrity was combined with an existing PHS-level office, the Office of Scientific Integrity Review.

\section{Anne Thomas}

DHHS Public Health Service,

National Institutes of Health,

Bethesda, Maryland 20892, USA 